\title{
Breast-conserving surgery following neoadjuvant therapy-a systematic review on surgical outcomes
}

\author{
José H. Volders ${ }^{1}$ - Vera L. Negenborn ${ }^{2} \cdot$ Pauline E. Spronk $^{3} \cdot$ Nicole M. A. Krekel ${ }^{2}$. Linda J. Schoonmade ${ }^{4}$ \\ Sybren Meijer ${ }^{1} \cdot$ Isabel T. Rubio $^{5} \cdot$ M. Petrousjka van den Tol ${ }^{1}$
}

Received: 26 June 2017 / Accepted: 7 August 2017 / Published online: 6 December 2017

(c) The Author(s) 2017. This article is an open access publication

\begin{abstract}
Purpose Neoadjuvant chemotherapy (NACT) is increasingly used in breast cancer treatment. One of the main goals of NACT is to reduce the extent of local surgery of the breast and axilla. The aim of this study was to determine surgical outcomes for patients receiving breast-conserving therapy (BCT) after NACT, including margin status plus secondary surgeries, excision volumes, and cosmetic outcomes.

Methods A systematic review was performed in accordance with PRISMA principles. Pubmed, MEDLINE, Embase, and the Cochrane Library were searched for studies investigating the results of BCT following NACT. The main study outcomes were margin status, additional local therapies, excision volumes, and cosmetic outcomes. Non-comparative studies on NACT were also included. Exclusion criteria were studies with less than 25 patients, and studies excluding secondary mastectomy patients. Findings Of the 1219 studies screened, 26 studies were deemed eligible for analysis, including data from 5379 patients treated with NACT and 10,110 patients treated without NACT. Included studies showed wide ranges of tumor-involved margins (2-39.8\%), secondary surgeries (0-45.4\%), and excision volumes $\left(43.2-268 \mathrm{~cm}^{3}\right)$ or specimen weight $(26.4-233 \mathrm{~g})$ after NACT. Most studies were retrospective, with a high heterogeneity and a high risk of bias. Cosmetic outcomes after NACT were reported in two single-center cohort studies. Both studies showed acceptable cosmetic outcomes.

Interpretation There is currently insufficient evidence to suggest that NACT improves surgical outcomes of BCT. It is imperative that clinical trials include patient outcome measures in order to allow monitoring and meaningful comparison of treatment outcomes in breast cancer.
\end{abstract}

Keywords Neoadjuvant chemotherapy $\cdot$ Breast-conserving therapy $\cdot$ Margins $\cdot$ Cosmetic outcome $\cdot$ Excision volume . Secondary mastectomy

The original version of this article was revised: Table 1 was published incorrectly and it was corrected in the article.

M. Petrousjka van den Tol

mp.vandentol@vumc.nl

1 Department of Surgical Oncology, VU University Medical Center, De Boelelaan 1117, Room 7F-020, 1081 HV Amsterdam, The Netherlands

2 Department of Plastic, Reconstructive and Hand Surgery, VU University Medical Center, Amsterdam, The Netherlands

3 Dutch Institute for Clinical Auditing, Leiden, The Netherlands

4 Medical Library, VU University Amsterdam, Amsterdam, The Netherlands

5 Breast Cancer Surgical Unit, Breast Cancer Center, Hospital Universitario Vall d'Hebron, Barcelona, Spain

\section{Introduction}

Neoadjuvant chemotherapy (NACT) is increasingly used in patients with operable breast cancer. Although these patients do not benefit in terms of survival and local recurrence (LRR) compared to adjuvant chemotherapy, NACT may have several advantages [1-3]. From a surgical point of view, NACT could reduce surgical morbidity of the breast and axilla. By downstaging of the tumor, NACT can convert patients who are candidates for mastectomy to breast-conserving surgery (BCS) candidates [1, 2]. Furthermore, it has potential to reduce excision volumes in patients with large tumors who are already candidates for BCS. Another surgical advantage is downstaging of the axilla so that axillary lymph node dissection can be avoided. Neoadjuvant therapy also permits an early evaluation of the effectiveness of systemic therapy. 
In studies involving BCS without NACT, breast conservation is associated with improved cosmetic outcomes and improved aspects of quality of life compared to mastectomy [4-8]. Additionally, smaller excision volumes positively influence cosmetic outcome after BCS [9-14]. Thereby, NACT may also improve cosmetic outcomes through conversion or by lowering resection volumes. However, international guidelines on the use of NACT in lowering breast resection volumes are currently lacking. Multidisciplinary approaches are depending on institutional facilities and expert opinions, resulting in an unaccountable variation between hospitals.

The two main goals of the surgeon when performing BCS are to obtain tumor-free margins and achieve a good cosmetic outcome by keeping the amount of healthy breast tissue excision as low as possible. Tumor-involved margins increase the risk of LRR and therefore require additional local therapy, such as a radiation therapy boost, re-excision, or even mastectomy. These treatments have a negative influence on cosmetic outcomes [9-15]. Unfortunately, the outcomes on margin status are known to be unsatisfactory in a large group of primary BCS patients. For example, a recent nationwide Dutch pathology study showed tumor-involved margins in $16.4 \%$ patients after primary BCS [16] and in the United States approximately one out of four patients will undergo one additional surgery after BCS [17]. Over the last decade, one out of three patients were reported to end up with a fair or poor cosmetic outcome [13, 15, 16, 18]. For this reason, surgeons have been investigating the improvement of surgical techniques such as shaved margins, oncoplastic breast surgery, and tumor localization with iodine-125 seeds and ultrasound-guided surgery [19-21].

The same goals as in BCS are being pursued in patients receiving BCS after NACT, although less is known about surgical outcomes. An additional challenge for surgeons performing BCS after NACT is determining the extent and original location of the residual lesion, especially after a good response to NACT.

The initial studies of NACT in breast cancer mainly focused on oncologic outcomes, chemotherapy regimens, molecular subtypes, and the treatment of the axilla. When considering NACT for downstaging of breast tumors, cosmetic outcome is becoming more important, especially since survival and local control is comparable to adjuvant chemotherapy.

\section{Objectives}

The objective of this systematic review was to describe and appraise the literature on surgical outcomes of BCS after NACT compared to adjuvant chemotherapy, including margin status and secondary local therapies, excision volumes, and cosmetic outcomes.

\section{Methods}

\section{Search strategy and selection criteria}

This systematic review was designed and carried out according to the principles of the PRISMA statement for reporting of systematic reviews [22]. A comprehensive search was performed in PubMed, Embase.com, and the Cochrane Library from inception up to May 17th, 2017. Search terms included controlled terms (MesH in PubMed, Emtree in Embase), as well as free text terms. We used free text terms only in The Cochrane Library. Search terms ('breast cancer OR breast neoplasm') were used in combination with (neoadjuvant OR induction OR primary systemic) AND (breast-conserving surgery or lumpectomy). Additional keywords (margin, volume, cosmetic outcome, aesthetic outcome) and further logical combinations of these and related terms were used to maximize sensitivity. The reference lists of all identified publications were checked to retrieve other relevant publications.

First, we included studies comparing neoadjuvant with adjuvant chemotherapy in women with operable breast cancer. Because no randomized controlled trials comparing neoadjuvant and adjuvant chemotherapy were found, retrospective and non-comparative studies, were included as well. The search was limited to articles published in English and Dutch. All studies investigating margin status plus the consequent additional local therapies, excision volumes, or cosmetic outcomes were included. No time limit was stipulated. Exclusion criteria were studies with less than 30 patients, studies without marking of the tumor before neoadjuvant therapy, and studies that excluded patients undergoing a secondary mastectomy due to margin involvement.

Two authors (JHV and VLN) independently screened and assessed the records for eligibility and extracted data from the articles. Disagreements on study eligibility were resolved either through consensus or by discussing with a third review author (SM). Whenever necessary, additional data from the authors of the articles were requested.

\section{Data analysis}

The primary outcomes for all studies were margin status with additional local therapies, excision volumes, and/or cosmetic outcomes. Tumor-involved margins were presented as a percentage of all patients undergoing BCS after NACT, while additional local therapies were divided into radiotherapy boost, re-excision, or secondary mastectomy and presented as a percentage of patients undergoing primary BCS after NACT. Excision volumes were reported 
as means in cc or as mean specimen weights in grams. Cosmetic outcomes could be evaluated subjectively by panel evaluation, by patient self-evaluation or by objective (computerized) measurements, depending on the study design. The Oxford Center for Evidence-Based Medicine (OCEBM) Levels of Evidence was used by both reviewers to help focus on the key concepts for evaluating the internal validity at study level [23]. Meta-analysis could not be performed due to heterogeneity among the studies.

\section{Results}

A total of 1219 unique articles were identified in the database search, after removing duplicates. Sixteen additional manuscripts were included after a manual search through the reference lists of the selected studies. In total, 1057 studies were excluded based on our predefined inclusion criteria after reading the abstracts. One hundred sixty-two articles were fully read and evaluated for reporting of margin status and additional therapy, volume, and/or cosmetic outcome. Eventually, 26 studies were deemed eligible (Fig. 1).

Two meta-analyses described survival and local recurrence rates being comparable between pre- and postoperative chemotherapy $[1,3]$. However, none of the studies included in these two meta-analyses reported margin status plus additional local therapies, excision volumes, or cosmetic outcomes.

\section{Margin status and additional local therapies}

In total, 22 studies mentioned margin status plus additional local therapies in patients receiving BCS after NACT [24-45] [Table 1]. All included studies showed a low level of evidence ( 3 or 4 ) on the OCEBM scoring system. Ten comparative studies described the surgical outcomes with or
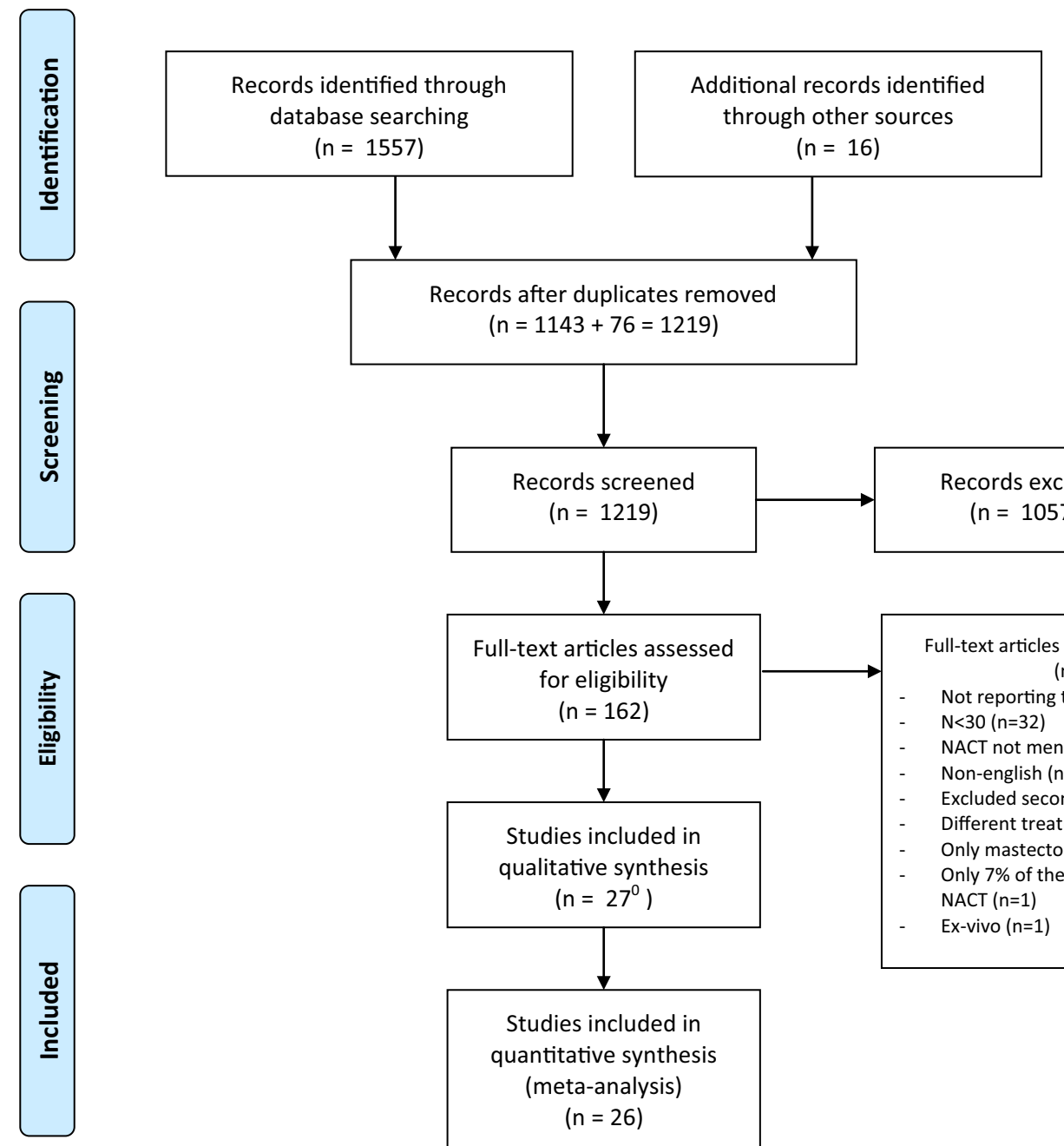

Records after duplicates removed $(n=1143+76=1219)$
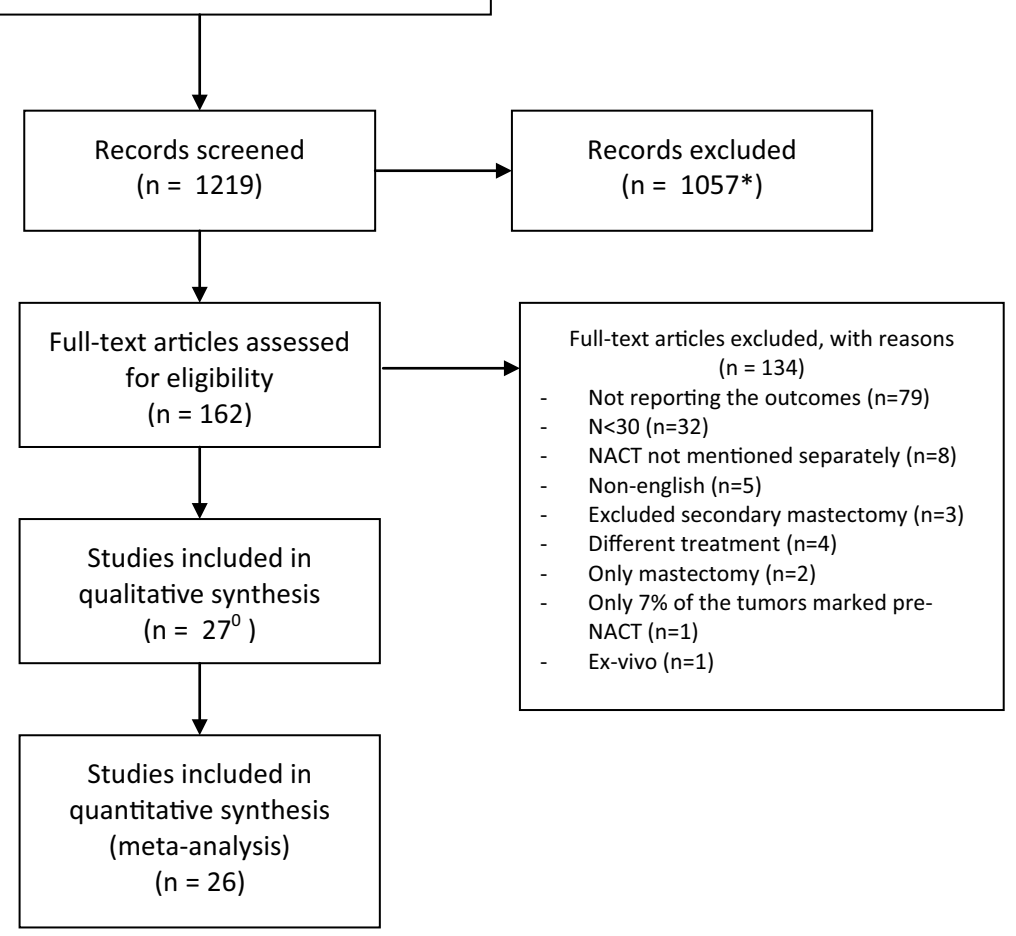

Fig. 1 PRISMA 2009 flow diagram. *Including $n=90$ abstracts eligible for inclusion but are conference abstracts only and were therefore excluded. 0 Articles by Tiezzi et al. [31] and Valejo et al. [55] report on the same group of study participants From Ref. [22] 
Table 1 Margin status and additional therapies

\begin{tabular}{|c|c|c|c|c|c|c|c|c|c|c|c|c|}
\hline Study & Study type & $\begin{array}{l}\text { Inclusion } \\
\text { period }\end{array}$ & Comparison & $\begin{array}{l}\text { BCS after } \\
\text { NACT (vs } \\
\text { primary BCS) }\end{array}$ & $\begin{array}{l}\text { Lobular } \\
\text { caricnoma } \\
\text { (\%) }\end{array}$ & $\begin{array}{l}\text { Definition } \\
\text { positive margin }\end{array}$ & $\begin{array}{l}\text { Positive } \\
\text { margins (\%) }\end{array}$ & $\begin{array}{l}\text { Additonal } \\
\text { boost (\%) }\end{array}$ & $\begin{array}{l}\text { Re-excision } \\
\text { (\%) }\end{array}$ & $\begin{array}{l}\text { secondary } \\
\text { mastectomy } \\
\text { (\%) }\end{array}$ & pCR (\%) & $\begin{array}{l}\text { OCEBM } \\
\text { evidence }\end{array}$ \\
\hline $\begin{array}{l}\text { Assersohn } \\
1999[24]\end{array}$ & $\begin{array}{l}\text { Randomized } \\
\text { controlled } \\
\text { trial }\end{array}$ & $1990-1995$ & $\begin{array}{l}\text { NACT } 4 x \text { plus } \\
\text { adjuvant } 4 x \text { vs } \\
8 x \text { adjuvant } \\
\text { chemotherapy }\end{array}$ & 98 vs 86 & NR & $\begin{array}{l}\text { inked margin } \\
\text { close }<1 \mathrm{~mm}\end{array}$ & $40 \%$ vs $36 \%$ & NR & $0 \%$ vs $0 \%$ & $0 \%$ vs $0 \%$ & NR & 3 \\
\hline $\begin{array}{l}\text { Boughey } \\
2006[25]\end{array}$ & $\begin{array}{l}\text { Prospective } \\
\text { cohort (RCT } \\
\text { data) }\end{array}$ & $1998-2005$ & $\begin{array}{l}\text { NACT vs } \\
\text { adjuvant } \\
\text { chemotherapy }\end{array}$ & 162 (vs 101) & NR & $\leq 2 \mathrm{~mm}$ & NR & NR & $\begin{array}{l}12.3 \% \text { vs } \\
13.9 \%\end{array}$ & $7.4 \%$ vs $9.9 \%$ & NR & 3 \\
\hline $\begin{array}{l}\text { Waljee } \\
2008[26]\end{array}$ & RSCC & $2002-2006$ & $\begin{array}{l}\text { NACT vs } \\
\text { adjuvant } \\
\text { chemotherapy }\end{array}$ & 65 (vs 211) & NR & NR & NR & NR & $\begin{array}{l}31.3 \% \text { vs } \\
58.8 \% \\
P=0.001\end{array}$ & $\begin{array}{l}14.1 \% \text { vs } \\
16.7 \% \\
P=0.001\end{array}$ & NR & 4 \\
\hline $\begin{array}{l}\text { Komenaka } \\
2011[27]\end{array}$ & RSCC & $2002-2009$ & $\begin{array}{l}\text { NACT vs } \\
\text { adjuvant } \\
\text { chemotherapy }\end{array}$ & 39 (vs 68) & NR & $\begin{array}{l}\text { inked margin } \\
\text { close }<1 \mathrm{~mm}\end{array}$ & $\begin{array}{l}23 \% \text { vs } 46 \% \\
\text { (close or } \\
\text { positive) } \\
\mathrm{P}=0.04\end{array}$ & NR & $\begin{array}{l}18 \% \text { vs } 41 \% \\
P=0.01\end{array}$ & $2.6 \%$ vs $8.8 \%$ & NR & 4 \\
\hline $\begin{array}{l}\text { Tiezzi } \\
2008[31]\end{array}$ & RSCC & $1990-2003$ & $\begin{array}{l}\text { NACT vs no } \\
\text { NACT }\end{array}$ & 88 (vs 191) & $\mathrm{NR}$ & $\leq 1 \mathrm{~mm}$ & $\begin{array}{l}19.3 \% \text { vs } \\
13.1 \%\end{array}$ & NR & $0 \%$ vs $0 \%$ & $0 \%$ vs $0 \%$ & NR & 4 \\
\hline $\begin{array}{l}\text { Christy } 2009 \\
\text { [29] }\end{array}$ & RSCC & $2002-2007$ & $\begin{array}{l}\text { NACT vs no } \\
\text { NACT }\end{array}$ & 31 (vs 62) & NR & $\begin{array}{l}\text { positive NR } \\
\text { close }<1 \mathrm{~mm}\end{array}$ & $\begin{array}{l}10 \% \text { vs } 32 \% \\
P<0.01\end{array}$ & NR & $\begin{array}{l}3.2 \% \text { vs } \\
17.7 \% \\
\mathrm{P}<0.01\end{array}$ & $\begin{array}{l}3.2 \% \text { vs } \\
21.0 \% \\
P<0.01\end{array}$ & NR & 4 \\
\hline $\begin{array}{l}\text { Karanlik } \\
2015 \text { [28] }\end{array}$ & RSCC & $2008-2011$ & $\begin{array}{l}\text { NACT vs no } \\
\text { NACT }\end{array}$ & 80 (vs 116) & NR & $<5 \mathrm{~mm}$ & $\begin{array}{l}5 \% \text { vs } 15.5 \% \\
P=0.02\end{array}$ & NR & $\begin{array}{l}3.8 \% \text { vs } 7.8 \% \\
P=0.02\end{array}$ & $\begin{array}{l}1.3 \% \text { vs } 7.8 \% \\
P=0.02\end{array}$ & NR & 4 \\
\hline $\begin{array}{l}\text { Volders } \\
2016[33]\end{array}$ & RSCC & $2012-2013$ & $\begin{array}{l}\text { NACT vs no } \\
\text { NACT }\end{array}$ & 626 (vs 9275) & $\begin{array}{l}11.3 \% \text { vs } \\
9.0 \%\end{array}$ & inked margin & $\begin{array}{l}27.3 \% \text { vs } \\
16.4 \% \\
p<0.001 \\
\end{array}$ & NR & $\begin{array}{l}4.0 \% \text { vs } 2.3 \% \\
p<0.001\end{array}$ & $\begin{array}{l}5.1 \% \text { vs } \\
3.0 \% \\
p<0.001\end{array}$ & $15 \%$ & 4 \\
\hline $\begin{array}{l}\text { Sadetzki } \\
2005[34]\end{array}$ & RSCC & $1995-2001$ & & 100 & $9 \%$ & $\begin{array}{l}<5 \mathrm{~mm} \\
\text { invasive } \\
<10 \mathrm{mn} \text { DCIS }\end{array}$ & NR & NR & $10 \%$ & $21 \%$ & NR & 4 \\
\hline $\begin{array}{l}\text { Fukutomi } \\
2006 \text { [35] }\end{array}$ & RSCC & NR & & 113 & NR & NR & $24.7 \%$ & NR & \multicolumn{2}{|c|}{2 nd procedures $11.5 \%$} & NR & 4 \\
\hline $\begin{array}{l}\text { Straver } \\
2010[36]\end{array}$ & RSCC & $2000-2007$ & & 135 & $15.6 \%$ & $\leq 2 \mathrm{~mm}$ & $24 \%$ & $15.6 \%$ & $1.5 \%$ & $6.7 \%$ & NR & 4 \\
\hline $\begin{array}{l}\text { van Riet } \\
2010[37] \\
\end{array}$ & RSCC & $2003-2008$ & & 47 & $6.4 \%$ & inked margin & $6.4 \%$ & $2.1 \%$ & & $4.3 \%$ & $40.4 \%$ & 4 \\
\hline $\begin{array}{l}\text { Gobardhan } \\
2012 \text { [38] }\end{array}$ & RSCC & $2009-2010$ & & 85 & $6 \%$ & inked margin & $8.2 \%$ & $4.8 \%$ & $0 \%$ & $3.5 \%$ & $31 \%$ & 4 \\
\hline $\begin{array}{l}\text { Mazouni } \\
2013[39]\end{array}$ & RSCC & $2002-2010$ & BCS vs OPBS & $\begin{array}{l}259 ; 214 \text { vs } \\
45\end{array}$ & $\begin{array}{l}6.1 \% \mathrm{vs} \\
4.4 \% \\
\end{array}$ & NR & $\begin{array}{l}14.1 \% \text { vs } \\
15.6 \%\end{array}$ & NR & $9 \%$ vs $2 \%$ & $18 \%$ vs $24 \%$ & $\begin{array}{l}24.3 \% \text { vs } \\
22.2 \%\end{array}$ & 4 \\
\hline $\begin{array}{l}\text { Donker } \\
2013[40]\end{array}$ & RSCC & $\begin{array}{l}2007- \\
2010\end{array}$ & $\begin{array}{l}\text { ROLL vs seed } \\
\text { localization }\end{array}$ & $154 ; 83$ vs 71 & $7 \%$ vs $4 \%$ & inked margin & $13 \%$ vs $13 \%$ & $\begin{array}{l}6.0 \% \text { vs } \\
4.2 \%\end{array}$ & $1 \%$ vs $4 \%$ & $6 \%$ vs $4 \%$ & $\begin{array}{l}30 \% \text { vs } \\
38 \%\end{array}$ & 4 \\
\hline $\begin{array}{l}\text { Gerber } \\
2014[41]\end{array}$ & $\begin{array}{l}\text { Multicenter } \\
\text { RCT }\end{array}$ & $2007-2010$ & $\begin{array}{l}\text { NACT ECDB vs } \\
\text { NACT ECD }\end{array}$ & 502 & NR & NR & $26.5 \%$ & NR & \multicolumn{2}{|c|}{ 2nd procedures $26.5 \%$} & NR & 3 \\
\hline $\begin{array}{l}\text { Krygh [30] } \\
2014\end{array}$ & RSCC & $2005-2012$ & $\begin{array}{l}\text { NACT vs no } \\
\text { NACT }\end{array}$ & 83 vs 1252 & NR & $\begin{array}{l}<5 \mathrm{~mm} \\
<2 \mathrm{~mm} \text { (after } \\
\text { oct 2009) }\end{array}$ & NR & NR & $\begin{array}{l}8.8 \% \text { vs } \\
10.3 \%\end{array}$ & NR & NR & 4 \\
\hline $\begin{array}{l}\text { Ramos } \\
2014 \text { [42] }\end{array}$ & $\begin{array}{l}\text { Prospective } \\
\text { single center } \\
\text { cohort }\end{array}$ & $2008-2012$ & & 58 & $5.2 \%$ & $<2 \mathrm{~mm}$ & $12.1 \%$ & $0(0 \%)$ & $6.9 \%$ & $5.2 \%$ & $31 \%$ & 4 \\
\hline $\begin{array}{l}\text { Amabile } \\
2015 \text { [32] }\end{array}$ & RSCC & $2009-2013$ & $\begin{array}{l}\text { NACT vs no } \\
\text { NACT }\end{array}$ & 44 vs 85 & $\begin{array}{l}2.3 \% \text { vs } \\
21.2 \%\end{array}$ & $\begin{array}{l}\text { positive } \\
\text { close }<1 \mathrm{~mm}\end{array}$ & $\begin{array}{l}27.3 \% \text { vs } \\
29.4 \% \\
\text { positive or } \\
\text { close }\end{array}$ & NR & \multicolumn{2}{|c|}{$\begin{array}{l}\text { 2nd procedures } 27.3 \% \text { vs } \\
29.3 \%\end{array}$} & $28.1 \%$ & 4 \\
\hline $\begin{array}{l}\text { Truin } \\
2016 \text { [43] }\end{array}$ & $\begin{array}{l}\text { Retrospective } \\
\text { national } \\
\text { database }\end{array}$ & $2008-2012$ & ILC VS IDC & $\begin{array}{l}1539 ; 113 \text { vs } \\
1426\end{array}$ & $\begin{array}{l}100 \% \text { vs } \\
0 \%\end{array}$ & NR & $\begin{array}{l}33.6 \% \text { vs } \\
8.6 \%\end{array}$ & NR & $7.1 \%$ vs $3.9 \%$ & $\begin{array}{l}26.5 \% \text { vs } \\
4.7 \%\end{array}$ & NR & 4 \\
\hline $\begin{array}{l}\text { Rubio } \\
2016[44]\end{array}$ & $\begin{array}{l}\text { Single center } \\
\text { cohort }\end{array}$ & $2008-2012$ & IOUS vs WL & $\begin{array}{l}214 ; 145 \text { vs } \\
69\end{array}$ & $\begin{array}{l}8.3 \% \text { vs } \\
2.9 \%\end{array}$ & inked margin & $3.4 \%$ vs $4.3 \%$ & NR & $\begin{array}{l}8.9 \% \text { vs } \\
2.9 \%\end{array}$ & $0.7 \%$ vs $5.8 \%$ & $\begin{array}{l}22.7 \% \text { vs } \\
34.7 \%\end{array}$ & 4 \\
\hline $\begin{array}{l}\text { Chauhan } \\
2016 \text { [45] }\end{array}$ & $\begin{array}{l}\text { Prospective } \\
\text { single center } \\
\text { cohort }\end{array}$ & $2012-2014$ & BCS vs OPBS & $100 ; 43$ vs 57 & $2 \%$ vs $2 \%$ & inked margin & $8 \%$ vs $2 \%$ & NR & $2 \%$ vs 0 & $5 \%$ vs $2 \%$ & NR & 4 \\
\hline
\end{tabular}

Breast Conserving Surgery, OPBS Oncoplastic Breast Surgery, RSCC Retrospective Single Center Cohort

without preoperative chemotherapy [24-33]. Positive margins in these comparative studies ranged from 5 to $39.8 \%$ after NACT versus $13.1-46 \%$ without NACT, leading to secondary surgery in $0-45.4 \%$ versus $0-76.5 \%$, respectively. Four retrospective studies reported a significantly lower number of involved margins and secondary surgery after NACT [23-26]. One study, based on a national pathology database describing 626 patients after NACT versus 9275 patients without NACT, reported a higher rate of involved margins $(27.3 \%$ vs. $16.4 \%)$ and secondary surgeries $(9.1 \%$ vs. 5.3\%) after NACT [33]. The other five studies showed no difference between both treatments.

Assersohn et al. reported a high rate of involved margins (39.8\% vs. $36.4 \%$ ) in the group receiving four cycles of neoadjuvant plus four cycles adjuvant chemo-endocrine therapy and the group receiving eight cycles of adjuvant chemoendocrine therapy. All systemic therapy was given concomitantly with radiotherapy and their policy was not to re-resect involved margins. One patient with involved margins had an breast tumor recurrence after a follow-up of 57 months. [24] 


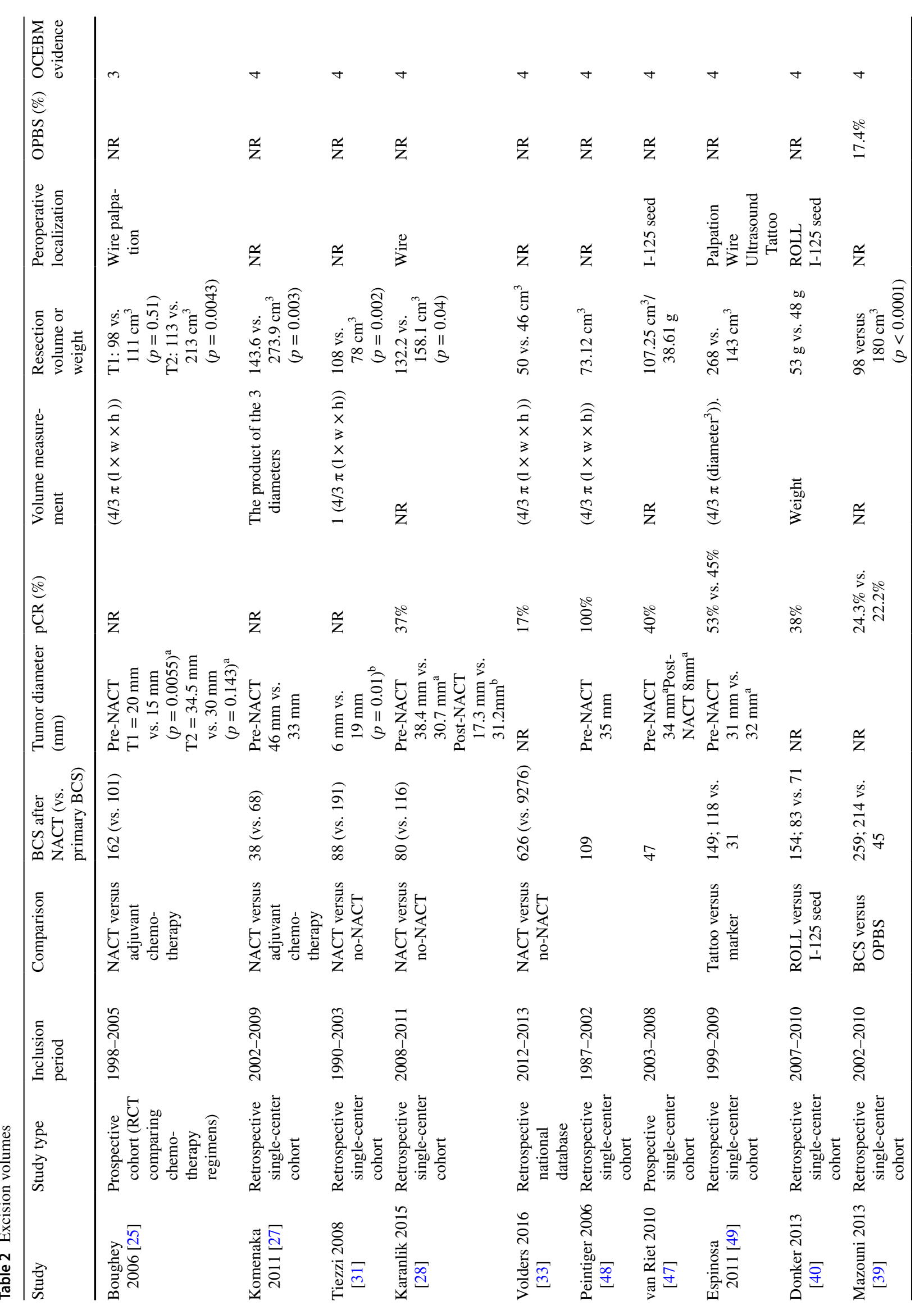




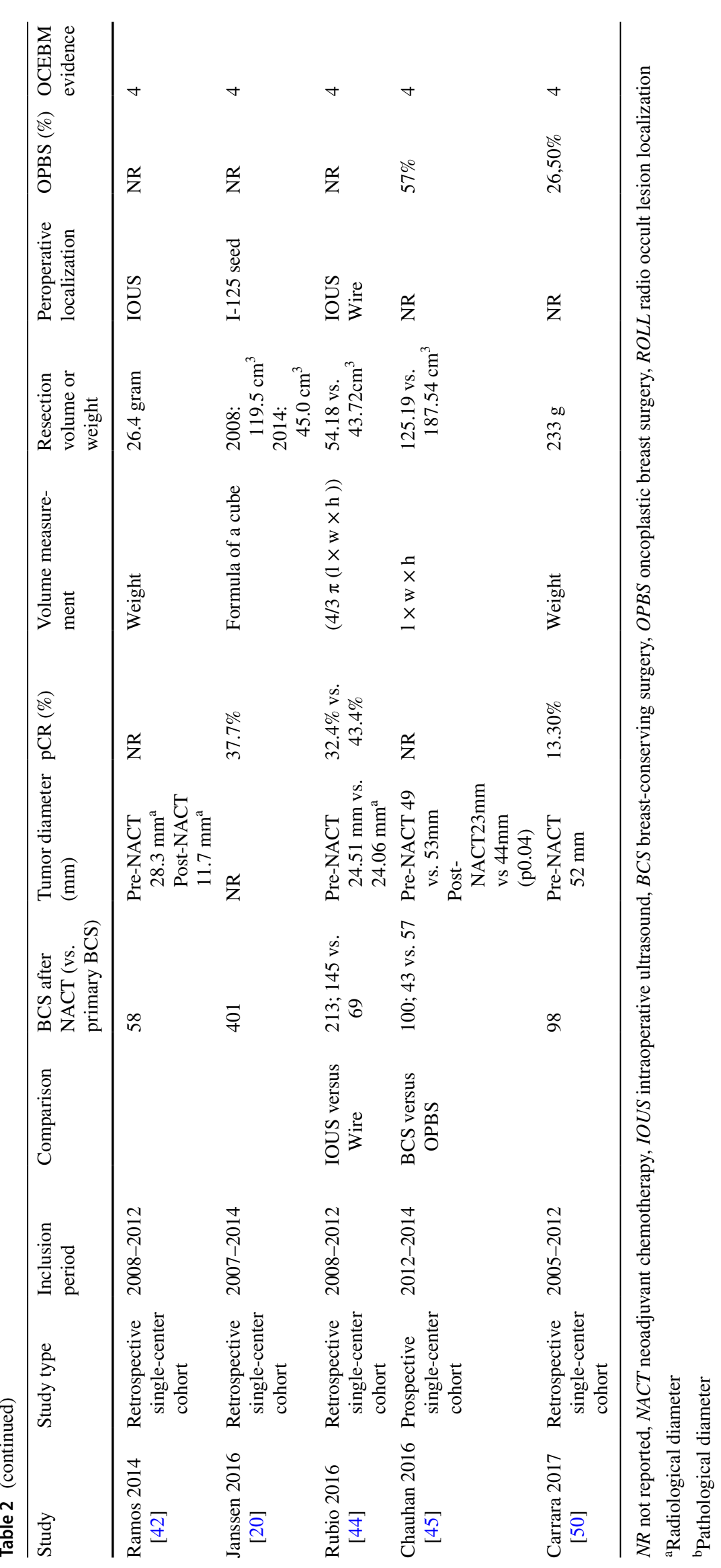


In a report by Tiezzi et al., re-excision was not performed in all 17 patients (19.3\%) with close/involved margins either due to refusal or to technical impossibility (posterior margin involving the major pectoral muscle fascia). A loco-regional recurrence rate of $11 \%$ was reported [31].

Twelve non-comparing studies reported $2-33.6 \%$ of tumor-involved margins after NACT followed by BCS, with $0-12.4 \%$ receiving a re-excision and $0.7-26.5 \%$ patients receiving a secondary mastectomy [34-45]. Two studies described secondary surgery after NACT ranging from 11.5 to $26.5 \%$, but this was not further specified as being either a re-excision or a mastectomy $[35,41]$. The presence of lobular carcinoma resulted in significantly higher degrees of tumor-involved margins compared with ductal carcinoma. $[33,36,43]$ For example, Truin et al. compared lobular carcinomas with ductal carcinomas and reported a secondary mastectomy rate of $26.5 \%$ versus $4.7 \%$, respectively [43].

\section{Excision volumes and cosmetic outcomes}

Excision volumes in patients undergoing BCS after NACT were reported in fifteen studies, including two prospective cohort studies and thirteen retrospective studies [20, 25, 27, $28,31,33,39,40,42,44,45,47,48-50]$. Thirteen studies were single-center studies. Again, all included studies showed a low level of evidence ( 3 or 4 ) on the OCEBM scoring system.

Mean excision volumes and weight ranged from $43.7-268 \mathrm{~cm}^{3}$ to $26.4-233 \mathrm{gr}$, respectively (Table 2). One study was based on data from a prospective randomized controlled trial and compared breast cancer patients receiving BCS before and after chemotherapy. Breast cancer patients with T1-T3, N0-N2 breast carcinoma were randomized between different chemotherapy regimens. The indication for administering pre- or postoperative chemotherapy was not randomized but made by the treating physicians, based on patient and tumor characteristics. In patients with $\mathrm{T} 1$ tumors, no significant difference was seen in excision volumes between the pre- and postoperative chemotherapy group, at $98 \mathrm{~cm}^{3}$ versus $111 \mathrm{~cm}^{3}$, respectively ( $p=0.51$ ). Tumor size at clinical presentation was $20 \mathrm{~mm}$ versus $15 \mathrm{~mm}$ ( $p=0.0055)$. In patients with $\mathrm{T} 2$ or T3 tumors, the mean excision volume was significantly lower in patients who received chemotherapy preoperatively $\left(113 \mathrm{~cm}^{3}\right.$ vs. $\left.213 \mathrm{~cm}^{3}, p=0.0043\right)$ with no difference in tumor size at presentation [25]. Four retrospective studies that compared BCS with or without NACT reported conflicting results [27, 28, 31,33]. Two studies showed lower excision volumes after NACT $\left(132.2 \mathrm{~cm}^{3}\right.$ vs. $158.1 \mathrm{~cm}^{3}, p=0.04$ and $143.6 \mathrm{~cm}^{3}$ vs. $273.9 \mathrm{~cm}^{3}$, $p<0.004)[27,28]$, whereas one study showed larger excision volumes following NACT $\left(108 \mathrm{~cm}^{3}\right.$ vs. $78 \mathrm{~cm}^{3}$, $p=0.002$ ) [31]. In a national pathology database study from the Netherlands, no difference was found between the use or absence of NACT in BCS $\left(50 \mathrm{~cm}^{3} \mathrm{vs} .46 \mathrm{~cm}^{3}\right.$, $p=0.14)$ [33].

Additionally, ten single-center cohort studies reported excision volumes or specimen weight after NACT without comparing these results with another group. A large heterogeneous patient population was included, and a wide range of excision volumes $\left(43.7-268 \mathrm{~cm}^{3}\right)$ and specimen weight $(48-233 \mathrm{~g})$ was reported $[20,39,40,42,44,45$, 47, 48-50].

No subanalyses regarding the predictive value of preoperative characteristics, for example, receptor status or histological subtype, and excision volumes were done in any of the fifteen studies. Four studies did analyze the influence of the response to NACT on the amount of volume excised. [33, 42, 44, 48] Volders et al. showed that the median lumpectomy volume in patients with no pathological response was $50 \mathrm{cc}$, with partial pathological response was $50 \mathrm{cc}$, and in patients with pathological (near) complete response median lumpectomy volume was $55 \mathrm{cc} .(p=0.018)$. The significant difference seems of low clinical value since there is only $5 \mathrm{cc}$ difference. Moreover, patients with partial and no pathological response had significant more involved margins compared to a pathological (near) complete response $(42.1,25.6$, and $12 \%$, respectively). Ramos et al. report no difference in case of complete pathological response (24.4 gr) versus partial response (27.4 gr). [42] Peintiger et al. reported no difference in clinical complete response versus clinical partial response (75.20 $\mathrm{cm}^{3}$ vs. $\left.66.78 \mathrm{~cm}^{3} p=0.53\right)$. [48] The volume excised in patients with pCR or minimal pathological residual tumor (Payne-Miller grades 4 and 5) was significantly lower after ultrasound-guided surgery compared to wire-guided surgery. [44].

Mazouni et al. described surgical outcomes of 214 patients after BCS and 45 patients treated with oncoplastic breast surgery (OPBS) after NACT. Excision volumes were smaller in the BCS group $\left(98 \mathrm{~cm}^{3}\right)$ compared with OPBS (98 vs. $\left.180 \mathrm{~cm}^{3}, p<0.0001\right)$ ). In the BCS group, $14.5 \%$ were moderately satisfied, $47.9 \%$ were satisfied and $37.6 \%$ were very satisfied with the cosmetic outcome, which was comparable to the OPBS group ( $p=0.52$ ) [39]. Karanlik et al. described 251 patients with $\mathrm{T} 2$ tumors receiving BCS for invasive breast cancer between 2008 and 2011. Excision volumes were smaller in the patients receiving NACT $\left(158.1 \mathrm{~cm}^{3}\right.$ vs. $\left.132.2 \mathrm{~cm}^{3}, p=0.04\right)$. Patients' pictures were evaluated independently by two nurses (median 12 months after surgery) [28]. A good/excellent cosmetic outcome was more common after NACT compared to patients receiving BCS without NACT (92\% vs. $80 \%, p=0.03)$. 


\section{Discussion}

\section{Margin status and secondary surgery}

Based on current data, there is no evidence supporting a positive effect of NACT on tumor-free margins and consequently, on a reduction of secondary surgery. This could be due to a variety of factors. Firstly, an insufficient number of prospective, controlled studies reporting the surgical outcomes have been conducted. Secondly, preoperative imaging and estimation of, non-concentric, residual disease during preoperative imaging appears to be more difficult after tumor downstaging. As a consequence, macroscopic evaluation of the location and extent of residual disease peri-operatively is complicated. It is beyond dispute that marking of the tumor after NACT is essential to achieve identification of residual tumor or the tumor bed and clear margins after BCS. Assessment of current literature indicates that an optimal method for localizing a non-palpable lesion after NACT has not yet been established [38, 40, 42, 44].

The frequency of reported pathological complete response (pCR) after NACT has increased dramatically in the past years due to improvements in targeted therapies, with up to half of all patients in specific groups such as HER2-positive patients [51]. From the studies included in this systematic review, pCR rates range from 12 to $40.4 \%$. [20, 31, 39, 40, 44, 47-50] By definition, these patients will have tumor-free resection margins, and therefore, the estimated percentages of involved margins are actually an underestimate in those patients who have residual disease after NACT. Currently, while the search continues for optimal preoperative imaging to predict response to NACT, the definitive response to chemotherapy is still determined postoperatively by a pathologist.

The importance of achieving tumor-free margins in patients who received BCS after NACT is a matter of debate, especially for patients with a good response to NACT. One of the arguments is the possibility of adjuvant radiotherapy to eradicate microscopic residual tumor and thereby decrease the rate of ipsilateral breast tumor recurrence (IBTR). In the 90s, Assersohn et al. showed a low (1.0\%) IBTR after 57 months in 98 patients receiving a 'sandwich' schedule of pre- and postoperative chemoendocrine therapy concomitant with radiotherapy. Breast cancer stages for the patients in the NACT group were not mentioned. Unfortunately, no data are available from prospective trials with current treatment strategies regarding margin width and oncological safety following NACT. In the NSAPB-B18 trial, a significant increase of IBTR was reported in patients who were converted from mastectomy to BCS when compared with those patients who had BCS as initially planned. After 9 years, the rates of IBTR were $15.9 \%$ versus $9.9 \%$, a difference that was no longer statistically significant after controlling for patient age and initial clinical tumor sizes [52].

The risk of bias across all included studies is high due to the retrospective character and variation among patient groups, especially in terms of selection and reporting bias. Comparison between studies is not possible and these studies therefore only reflect the current (selected) surgical outcomes after NACT. In general, the group that received preoperative chemotherapy had larger and biologically more aggressive tumors, factors that would be expected to increase the rate of positive margins and re-excision [29]. On the other hand, the studies that did not involve NACT included more lobular carcinomas, which is known to have a higher risk of involved margins.

Nonetheless, the primary goal of every surgeon when starting BCS after NACT is to excise the tumor without tumor-involved margins. Involved margins result in more frequent secondary surgery, leading to poor cosmetic outcomes, additional costs, and psychological stress for the patient. Clinical studies regarding neoadjuvant therapy in breast cancer have mainly been initiated by oncologists, resulting in a degree of neglect of surgical outcomes, a problem illustrated by the lack of data on margin status and excision volumes in randomized controlled trials.

Our view is that both oncological and surgical outcomes after NACT should be assessed equally as the latter positively contributes to a patient's quality of life, as extensively reported in the adjuvant setting [53, 54]. Furthermore, the distress associated with secondary surgery is also underrecognized in surgical studies. For example, Truin et al. describe 30 secondary mastectomies in 466 patients with lobular cancer undergoing BCS after NACT, concluding that $6.4 \%$ of patients undergo a secondary mastectomy [43]. The correct calculation would have included primary lumpectomies only, resulting in a figure of $26.5 \%$ (30 secondary mastectomies of 113 primary lumpectomies) (Fig. 1). Patients with invasive lobular carcinoma will have lower pathological complete response ( $\mathrm{pCR}$ ) rates and higher rates of secondary surgery due to positive margins and should therefore be informed about these negative outcomes.

\section{Excision volume}

Neoadjuvant chemotherapy could potentially improve cosmetic outcomes by reducing the volume of excised breast tissue in candidates for both mastectomy and BCS. Among patients with T2 tumors, two studies showed that patients treated with NACT underwent less extensive excision compared with those who underwent primary surgery. Moreover, the smaller resected volumes did not lead to increased risk of re-excision to obtain negative margins 
[25, 28]. By contrast, Tiezzi et al. reported larger resection volumes in patients after NACT, although it should be noted that these tumors were larger at presentation [31]. It is important to realize that larger volumes do not necessarily result in fewer involved margins or less additional therapy.[16, 25, 27, 47].

With the advent of NACT, the challenge for surgeons became to localize the remaining lesion and to resect the minimum amount of healthy breast tissue, while achieving tumor-free margins.

The pattern of tumor regression is not always concentric and may also occur with diffuse fragmentation. Therefore, the concern of leaving microscopic residual tumor surrounding the surgical area after NACT resulted in a dilemma of how much breast tissue to excise. Plainly, it is not necessary to excise the original tumor volume, otherwise all advantages of performing NACT for downstaging of the breast will vanish [25].

Due to the retrospective and non-comparative design of the currently available single-center cohort studies, no general conclusion can be drawn. The results only reflect the current volumes resected after NACT. Cosmetic failure rates have proven to be significantly higher if the size of the lumpectomy exceeds 40-100 cc, regardless of breast size [9, $12,13,18]$. Keeping this in mind, almost all of the studies report extremely high excision volumes after NACT, probably resulting in poor cosmetic outcomes for these patients. It would have been of great value if certain subgroups were analyzed for their predictive value on resection volumes, but unfortunately no conclusion can be drawn from the current literature regarding the impact of, for example, receptor status, histological subtype, or chemotherapy regimen on excision volume and cosmetic outcome. The calculated resection ratio (CRR), which is the total resection volume divided by the optimal resection volume, is a measure to assess excessive breast tissue resection. Only one study reported a resection ratio, with a median CRR in the primary surgery and neoadjuvant therapy groups of 3.3 and 2.0, respectively $(p<0.0001)$. This implies that the excision volumes were 2-3.3 times as large as they should be [55].

\section{Cosmetic outcome}

With improvements in NACT strategies, and the increasing rates of $\mathrm{pCR}$ with a good prognosis, cosmetic outcomes are becoming increasingly important to breast cancer patients. Unfortunately, any evidence supporting an improvement of cosmetic outcomes after tumor downstaging with NACT is currently lacking. Two single-center retrospective studies reported acceptable results, but included small and highly selected study groups, with a large risk of bias [28, 39]. A poor cosmetic outcome of the breast following breast cancer treatment has a high impact on patients' quality of life, being a daily reminder of their previous breast cancer and of their treatment period. For this reason, a thorough counseling of patients on the expected primary and secondary outcomes of their treatment is mandatory. In particular, patients receiving NACT to convert from mastectomy to BCS, may have high expectations regarding their cosmetic outcomes and may therefore be unprepared for poor cosmetic results. In particular, when realizing that cosmetic outcomes after a mastectomy with a breast reconstruction may have very satisfactory results as well [7].

One of the main indications for NACT in breast cancer patients to date is tumor downstaging to achieve less morbidity and improved cosmetic outcomes. However, it is interesting that these outcomes of NACT are not supported by any scientific evidence.

The motivation for use of NACT to downstage the breast tumor is based on two facts regarding BCS without NACT:

1. BCS patients have improved cosmetic outcomes and quality of life compared to mastectomy patients [4-8].

2. Excision volume is one of the most important factors determining cosmetic outcome in patients after BCS [9-15, 18].

However, these statements are both based on studies without NACT. Although BCS appears technically feasible in patients receiving NACT after tumor downstaging, a satisfactory cosmetic outcome cannot be guaranteed when still a large amount of breast tissue is resected.

The negative influence of large resection volumes on cosmetic outcomes and the frequent poor cosmetic outcome of BCS without NACT validate current efforts to improve cosmetic outcomes with oncoplastic breast surgery (OPBS). The theoretical advantage of oncoplastic surgery for breast cancer is the possibility of using wider resection margins, leading to improved oncological outcomes and less secondary local therapies, combined with a good cosmetic result. However, involved margins and secondary local therapies after OPBS are still frequently reported [56, 57]. Unfortunately, current literature on OPBS without NACT largely consists of poorly designed and underpowered studies, while high-quality literature on OPBS in patients receiving BCS after NACT is absent. Mazouni et al. reported high rates of involved margins $(15.6 \%)$ and secondary mastectomies $(25 \%)$ in OPBS after NACT, while no difference in cosmetic outcome was seen compared to BCS after NACT.[39] Amabile et al. reported secondary mastectomy in $27.3 \%$ of patients after NACT followed by OPBS [32].

In conclusion, the advantages of NACT in terms of lower resection volumes and improved cosmetic outcomes after BCT have not yet been proven. Prospective randomized trials including secondary local therapies, 
resection volumes, and cosmetic outcomes in patients receiving postoperative chemotherapy, as well as reporting the type of initial surgery, will be required to confirm the hypothesis that NACT improves cosmetic outcomes by lowering excision volumes. In a new era of neoadjuvant treatments, it is imperative for surgeons to include not only outcomes of surgical techniques in their routine clinical practice, but also to take note of patient outcome measures in order to better monitor and compare surgical treatment outcomes in meaningful ways.

Funding None of the authors have a financial relationship regarding the study, and there was no organization that sponsored the research.

Author's contribution J.V.: Study design, search and screening of articles, collection and interpretation of data, writing of the manuscript, critical revision and final approval of the manuscript, agreement to be accountable for the work. V.L.N.: Study design, search screening of articles, collection and interpretation of data, writing of the manuscript, critical revision and final approval of the manuscript, agreement to be accountable for the work. P.S: Substantial contribution to study design and data interpretation, critical revision and final approval of the manuscript, agreement to be accountable for the work. N.M.A.K.: Substantial contribution to study design and data interpretation, critical revision and final approval of the manuscript, agreement to be accountable for the work. L.S.: Study search, data interpretation, critical revision and final approval of the manuscript, agreement to be accountable for the work. S.M.: Substantial contribution to study design and data interpretation, critical revision and final approval of the manuscript, agreement to be accountable for the work. I.T.R: Substantial contribution to study design and data interpretation, critical revision and final approval of the manuscript, agreement to be accountable for the work. M.P.v.d.T: Substantial contribution to study design and data interpretation, critical revision and final approval of the manuscript, agreement to be accountable for the work.

\section{Compliance with ethical standards}

Conflict of interest The authors declare that they have no conflict of interest.

Open Access This article is distributed under the terms of the Creative Commons Attribution 4.0 International License (http://creativecomm ons.org/licenses/by/4.0/), which permits unrestricted use, distribution, and reproduction in any medium, provided you give appropriate credit to the original author(s) and the source, provide a link to the Creative Commons license, and indicate if changes were made.

\section{References}

1. Mieog JSD, van der Hage JA, van de Velde CJH (2007) Preoperative chemotherapy for women with operable breast cancer. Cochrane Database Syst Rev. doi:10.1002/14651858.CD005002 .pub2

2. Mittendorf EA, Buchholz TA, Tucker SL et al (2013) Impact of chemotherapy sequencing on local-regional failure risk in breast cancer patients undergoing breast-conserving therapy. Ann Surg 257(2):173-179. doi:10.1097/SLA.0b013e3182805c4a
3. Mauri D, Pavlidis N, Ioannidis JPA (2005) Neoadjuvant versus adjuvant systemic treatment in breast cancer: a meta-analysis. JNCI J Natl Cancer Inst 97(3):188-194. doi:10.1093/jnci/dji021

4. Curran D, Van Dongen JP, Aaronson NK, Kiebert G, Fentiman IS, Mignolet F (1998) Quality of life of early-stage breast cancer patients treated with radical mastectomy or breast-conserving procedures: results of EORTC Trial 10801. Eur J Cancer 34(3):307-314

5. Kim MK, Kim T, Moon HG et al (2015) Effect of cosmetic outcome on quality of life after breast cancer surgery. Eur J Surg Oncol 41(3):426-432. doi:10.1016/j.ejso.2014.12.002

6. Arndt V, Stegmaier C, Ziegler H, Brenner H (2008) Quality of life over 5 years in women with breast cancer after breast-conserving therapy versus mastectomy: a population-based study. J Cancer Res Clin Oncol 134(12):1311-1318. doi:10.1007/s00432-0080418-y

7. Jagsi R, Li Y, Morrow M et al (2015) Patient-reported quality of life and satisfaction with cosmetic outcomes after breast conservation and mastectomy with and without reconstruction. Ann Surg 261(6):1198-1206. doi:10.1097/SLA.0000000000000908

8. Markopoulos C, Tsaroucha AK, Kouskos E, Mantas D, Antonopoulou Z, Karvelis S (2009) Impact of breast cancer surgery on the self-esteem and sexual life of female patients. J Int Med Res 37(1):182-188

9. Vrieling C, Collette L, Fourquet A et al (2000) The influence of patient, tumor and treatment factors on the cosmetic results after breast-conserving therapy in the EORTC "boost vs. no boost" trial. Radiother Oncol 55(3):219-232. doi:10.1016/S0167-8140 (00)00210-3

10. Immink JM, Putter H, Bartelink H et al (2012) Long-term cosmetic changes after breast-conserving treatment of patients with stage I-II breast cancer and included in the EORTC "boost versus no boost" trial. Ann Oncol 23(10):2591-2598. doi:10.1093/anno nc/mds066

11. Cochrane RA, Valasiadou P, Wilson ARM, Al-Ghazal SK, Macmillan RD (2003) Cosmesis and satisfaction after breast-conserving surgery correlates with the percentage of breast volume excised. Br J Surg 90(12):1505-1509. doi:10.1002/bjs.4344

12. Taylor M, Perez C, Halverson K et al (1995) Factors influencing cosmetic results after conservation therapy for breast cancer. Int J Radiat Oncol Biol Phys 31(4):753-764. doi:10.1016/0360-3016 (94)00480-3

13. Hennigs A, Hartmann B, Rauch G et al (2015) Long-term objective esthetic outcome after breast-conserving therapy. Breast Cancer Res Treat 153(2):345-351. doi:10.1007/s10549-015-3540-y

14. Haloua MH, Volders JH, Krekel NMA et al (2016) Intraoperative ultrasound guidance in breast-conserving surgery improves cosmetic outcomes and patient satisfaction: results of a multicenter randomized controlled trial (COBALT). Ann Surg Oncol 23(1):30-37. doi:10.1245/s10434-015-4906-4

15. Parvez E, Cornacchi SD, Hodgson N et al (2014) A cosmesis outcome substudy in a prospective, randomized trial comparing radioguided seed localization with standard wire localization for nonpalpable, invasive, and in situ breast carcinomas. Am J Surg 208(5):711-718. doi:10.1016/j.amjsurg.2014.05.030

16. Haloua MH, Volders JH, Krekel NMA et al (2016) A nationwide pathology study on surgical margins and excision volumes after breast-conserving surgery: there is still much to be gained. Breast 25:14-21. doi:10.1016/j.breast.2015.11.003

17. Wilke LG, Czechura T, Wang C et al (2014) Repeat surgery after breast conservation for the treatment of stage 0 to II breast carcinoma: a report from the National Cancer Data Base, 20042010. JAMA Surg. 149(12):1296-1305. doi:10.1001/jamasurg .2014 .926

18. Hill-Kayser CE, Vachani C, Hampshire MK, Di Lullo GA, Metz JM (2012) Cosmetic outcomes and complications reported by 
patients having undergone breast-conserving treatment. Int $\mathrm{J}$ Radiat Oncol Biol Phys 83(3):839-844. doi:10.1016/j.ijrobp.2011 .08 .013

19. Krekel NMA, Haloua MH, Lopes Cardozo AMF et al (2013) Intraoperative ultrasound guidance for palpable breast cancer excision (COBALT trial): a multicentre, randomised controlled trial. Lancet Oncol. 14(1):48-54. doi:10.1016/S1470-2045(12)70527-2

20. Janssen NNY, Nijkamp J, Alderliesten T et al (2016) Radioactive seed localization in breast cancer treatment. Br J Surg 103(1):70 80. doi:10.1002/bjs. 9962

21. Chagpar AB, Killelea BK, Tsangaris TN et al (2015) A randomized, controlled trial of cavity shave margins in breast cancer. N Engl J Med 373(6):503-510. doi:10.1056/NEJMoa1504473

22. Moher D, Liberati A, Tetzlaff J, Altman DG, Grp P (2009) Preferred reporting items for systematic reviews and meta-analyses: the PRISMA statement (Reprinted from annals of internal medicine). Phys Ther 89(9):873-880. doi:10.1371/journal.pmed.1000 097

23. Howick J, Chalmers I, Glasziou P, et al. The Oxford 2011 levels of evidence. Oxford centre evidence-based medicine. Vol 1. 2011. http://www.cebm.net/index.aspx?o=1025

24. Assersohn L, Powles TJ, Ashley S et al (1999) Local relapse in primary breast cancer patients with unexcised positive surgical margins after lumpectomy, radiotherapy and chemoendocrine therapy. Ann Oncol 10(12):1451-1455. doi:10.1023/A:10083713 18784

25. Boughey JC, Peintinger F, Meric-Bernstam F et al (2006) Impact of preoperative versus postoperative chemotherapy on the extent and number of surgical procedures in patients treated in randomized clinical trials for breast cancer. Ann Surg 244(3):464-470. doi:10.1097/01.sla.0000234897.38950.5c

26. Waljee JF, Hu ES, Newman LA, Alderman AK (2008) Predictors of re-excision among women undergoing breast-conserving surgery for cancer. Ann Surg Oncol 15(5):1297-1303. doi:10.1245/ s10434-007-9777-x

27. Komenaka IK, Hibbard ML, Hsu C-H et al (2011) Preoperative chemotherapy for operable breast cancer improves surgical outcomes in the community hospital setting. Oncologist 16(6):752759. doi:10.1634/theoncologist.2010-0268

28. Karanlik H, Ozgur I, Cabioglu N et al (2015) Preoperative chemotherapy for T2 breast cancer is associated with improved surgical outcome. Eur J Surg Oncol 41(9):1226-1233. doi:10.1016/j.ejso .2015.06.003

29. Christy CJ, Thorsteinsson D, Grube BJ et al (2009) Preoperative chemotherapy decreases the need for re-excision of breast cancers between 2 and $4 \mathrm{~cm}$ diameter. Ann Surg Oncol 16(3):697-702. doi:10.1245/s10434-008-0268-5

30. Kryh CG, Pietersen CA, Rahr HB, Christensen RD, Wamberg P, Lautrup MD (2014) Re-resection rates and risk characteristics following breast conserving surgery for breast cancer and carcinoma in situ: a single-centre study of 1575 consecutive cases. Breast 23(6):784-789. doi:10.1016/j.breast.2014.08.011

31. Tiezzi DG, Andrade JM, Marana HRC, Zola FE, Peria FM (2008) Breast conserving surgery after neoadjuvant therapy for large primary breast cancer. Eur J Surg Oncol 34(8):863-867. doi:10.1016 /j.ejso.2008.01.015

32. Amabile MI, Mazouni C, Guimond C, Sarfati B, Leymarie N, Cloutier AS, Bentivegna E, Garbay JR, Kolb F, Rimareix F (2015) Factors predictive of re-excision after oncoplastic breast-conserving surgery. Anticancer Res 35(7):4229-4234

33. Volders JH, Haloua MH, Krekel NMA et al (2016) Neoadjuvant chemotherapy in breast-conserving surgery-consequences on margin status and excision volumes. Eur J Surg Oncol. doi:10.1016 /j.ejso.2016.02.252
34. Sadetzki S, Oberman B, Zipple D et al (2005) Breast conservation after neoadjuvant chemotherapy. Ann Surg Oncol 12(6):480-487. doi:10.1245/ASO.2005.07.021

35. Fukutomi T (2006) Clinical practice and outcome of breastconserving treatment: the effectiveness of preoperative systemic chemotherapy. Breast Cancer 13(2):147-151

36. Straver ME, Rutgers EJT, Rodenhuis S et al (2010) The relevance of breast cancer subtypes in the outcome of neoadjuvant chemotherapy. Ann Surg Oncol 17(9):2411-2418. doi:10.1245/s104 34-010-1008-1

37. Van Riet YEA, Maaskant AJG, Creemers GJ et al (2010) Identification of residual breast tumour localization after neo-adjuvant chemotherapy using a radioactive 125 Iodine seed. Eur J Surg Oncol 36(2):164-169. doi:10.1016/j.ejso.2009.10.009

38. Gobardhan PD, De Wall LL, Van Der Laan L et al (2012) The role of radioactive iodine- 125 seed localization in breast-conserving therapy following neoadjuvant chemotherapy. Ann Oncol. doi:10.1093/annonc/mds475

39. Mazouni C, Naveau A, Kane A et al (2013) The role of oncoplastic breast surgery in the management of breast cancer treated with primary chemotherapy. Breast 22(6):1189-1193. doi:10.1016 /j.breast.2013.07.055

40. Donker M, Drukker CA, Valdés Olmos RA (2013) Guiding breastconserving surgery in patients after neoadjuvant systemic therapy for breast cancer:a comparison of radioactive seed localization with the ROLL technique. Ann Surg Oncol. doi:10.1245/s104 34-013-2921-x

41. Gerber B, von Minckwitz G, Eidtmann H et al (2014) Surgical outcome after neoadjuvant chemotherapy and bevacizumab: results from the GeparQuinto study (GBG 44). Ann Surg Oncol 21(8):2517-2524. doi:10.1245/s10434-014-3606-9

42. Ramos M, Díez JC, Ramos T, Ruano R, Sancho M, GonzálezOrús JM (2014) Intraoperative ultrasound in conservative surgery for non-palpable breast cancer after neoadjuvant chemotherapy. Int J Surg. 12(6):572-577. doi:10.1016/j.ijsu.2014.04.003

43. Truin W, Vugts G, Roumen RMH et al (2016) Differences in response and surgical management with neoadjuvant chemotherapy in invasive lobular versus ductal breast cancer. Ann Surg Oncol 23(1):51-57. doi:10.1245/s10434-015-4603-3

44. Rubio IT, Esgueva-colmenarejo A, Espinosa-bravo M, Salazar JP, Miranda I, Peg V (2016) Intraoperative ultrasound-guided lumpectomy versus mammographic wire localization for breast cancer patients after neoadjuvant treatment. Ann Surg Oncol. doi:10.1245/s10434-015-4935-z

45. Chauhan A, Sharma MM, Kumar K (2016) Evaluation of surgical outcomes of oncoplasty breast surgery in locally advanced breast cancer and comparison with conventional breast conservation surgery. Indian J Surg Oncol 7(4):413-419. doi:10.1007/s131 93-016-0549-6

46. Krekel NM, Zonderhuis B, Muller S, Bril H, van Slooten HJ, de Lange de Klerk E, van den Tol P, Meijer S (2011) Excessive resections in breast-conserving surgery: a retrospective multicentre study. Breast J. 17(6):602-609. doi:10.1111/j.1524-4741.2011 .01198.X

47. van Riet YEA, Maaskant AJG, Creemers GJ et al (2010) Identification of residual breast tumour localization after neo-adjuvant chemotherapy using a radioactive 125 Iodine seed. Eur J Surg Oncol 36(2):164-169. doi:10.1016/j.ejso.2009.10.009

48. Peintinger F, Symmans WF, Gonzalez-Angulo AM et al (2006) The safety of breast-conserving surgery in patients who achieve a complete pathologic response after neoadjuvant chemotherapy. Cancer 107(6):1248-1254. doi:10.1002/cncr.22111

49. Espinosa-Bravo M, Sao Avilés A, Esgueva A et al (2011) Breast conservative surgery after neoadjuvant chemotherapy in breast cancer patients: comparison of two tumor localization methods. 
Eur J Surg Oncol 37(12):1038-1043. doi:10.1016/j.ejso.2011 .08 .136

50. Carrara GF, Scapulatempo-Neto C, Abrahão-Machado LF (2017) Breast-conserving surgery in locally advanced breast cancer submitted to neoadjuvant chemotherapy. Safety and effectiveness based on ipsilateral breast tumor recurrence and long-term followup. Clinics (Sao Paulo) 72(3):134-142. doi:10.6061/clinics/2017 (03)02

51. Baselga J, Bradbury I, Eidtmann H et al (2012) Lapatinib with trastuzumab for HER2-positive early breast cancer (NeoALTTO): a randomised, open-label, multicentre, phase 3 trial. Lancet 379(9816):633-640. doi:10.1016/S0140-6736(11)61847-3

52. Wolmark N, Wang J, Mamounas E, Bryant J, Fisher B (2001) Preoperative chemotherapy in patients with operable breast cancer: nine-year results from national surgical adjuvant breast and bowel project B-18. JNCI Monogr (30): 96-102. http://jncimono .oxfordjournals.org/content/2001/30/96.abstract

53. Waljee JF, Hu ES, Ubel P, Smith DM, Newman L, Alderman AK (2008) Effect of esthetic outcome after breast-conserving surgery on psychosocial functioning and quality of life. J Clin Oncol 26(20):3331-3337. doi:10.1200/JCO.2007.13.1375
54. Al-Ghazal SK, Fallowfield L, Blamey RW (1999) Does cosmetic outcome from treatment of primary breast cancer influence psychosocial morbidity? Eur J Surg Oncol 25(6):571-573. doi:10.1053/ejso.1999.0708

55. Valejo FAM, Tiezzi DG, Mandarano LRM, de Sousa CB, de Andrade JM (2013) Volume of breast tissue excised during breastconserving surgery in patients undergoing preoperative systemic therapy. Rev Bras Ginecol e Obstet Rev da Fed Bras das Soc Ginecol e Obstet. 35(5):221-225. doi:10.1590/S0100-72032013 000500006

56. Clough KB, Ihrai T, Oden S, Kaufman G, Massey E, Nos C (2012) Oncoplastic surgery for breast cancer based on tumour location and a quadrant-per-quadrant atlas. Br J Surg 99(10):1389-1395. doi: $10.1002 / b j s .8877$

57. Haloua MH, Krekel NM, Winters HAH et al (2013) A systematic review of oncoplastic breast-conserving surgery: current weaknesses and future prospects. Ann Surg 257(4):609-620. doi:10.1097/SLA.0b013e3182888782 